\section{A CASE OF CONJOINED TWINS}

NTINOS C. MYRIANTHOPOULOS, BRIGITTE DE LA BURDE

National Institute of Neurological Diseases and Stroke, NIH, Bethesda, Maryland, USA

Medical College of Virginia, Richmond, Virginia, USA

Among 56,249 maternities in the Collaborative Perinatal Project, 6I 5 were twin maternities. One of these resulted in stillborn thoraco-omphalopagus female twins with multiple cardiovascular, alimentary, and other malformations. The case is of further interest in that the mother had a surgically removed brain tumor in childhood and exhibited neurological symptoms and bizarre behavior before and during pregnancy. Drugs and treatments which she received during pregnancy are not known to be teratogenic.

Ntinos C. Myrianthopoulos, NINDS, NIH, Bethesda, Maryland 20014, USA

\section{MONOAMNIOTIC TWINS}

\section{RAGNA FOGLMANN}

Department of Obstetrics, St. Foseph Hospital, Copenhagen, Denmark

Department of Obstetrics, Frederiksberg Hospital, Copenhagen, Denmark

Monoamniotic twin pregnancy is a rare condition, which occurs when the twins are contained in a single sac.

Six new cases of monoamniotic twins, born at the Departments of Obstetrics of St. Josephs and Frederiksberg Hospitals, are reported. All had true knots of the cords, the result being double survival in five cases and eleven normal children.

The mechanism of twin development is described and monoamniotic twins are placed in accordance with the two theories from the literature.

A short review of both the Scandinavian and the world cases is presented.

In one of the new cases, we have a clearly dividing plica, possibly caused by a spontaneous or traumatic disruption of a previous diamniotic membrane; however, genetic examinations showed truly identical boys.

Dr. Ragna Foglmann, Kattesundet 2/2 DK-1458, Copenhagen, Denmark
FAMILIAL TWINNING: A POSSIBLE EXAMPLE OF SUPERFETATION IN MAN

\author{
S. A. RHINE, W. E. NANGE, J. R. MELIN, \\ C. E. SKIDMORE
}

Department of Medical Genetics, Indiana University School of Medicine, Indianapolis, Indiana, USA

Studies of individual families and interracial crosses have generally suggested that sex-limited genetic factors in the mother influence the frequency of $\mathrm{DZ}$ twinning. However we have observed a family, shown below, in which the tendency to bear twins was expressed in the offspring of males as well as females. All of the twins born in this family were also unusual because of marked discordance in birth weight and gestational age. In five of the six pairs, one twin was normal while the other was either a macerated fetal mass, stillborn, or died of prematurity in the neonatal period.

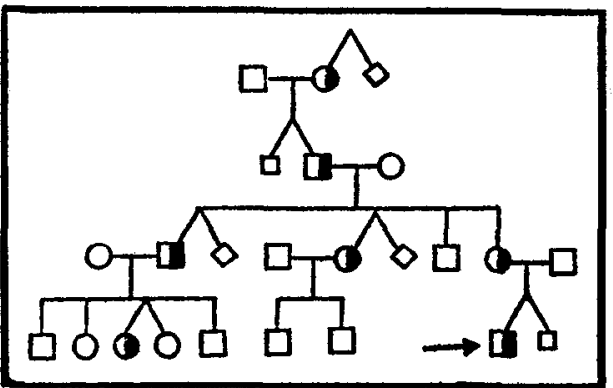

The one pair in which both twins did survive is known to be $\mathrm{DZ}$ and showed a difference in maturity and a $21 \%$ discrepancy in birth weight (230og as compared to I850g). Thus, twinning in this family appears to be transmitted as an autosomal dominant trait which is expressed in the offspring of both female and male carriers. Genetic mechanisms which could possibly explain this familial aggregation of markedly discordant twins include heritable meiotic abnormalities which lead to polar-body twinning, delayed implantation of the embryo, retarded or arrested intrauterine development, and superfetation. Of all these possibilities, superfetation seems most consistent with the genetic transmission and expression of the trait in the offspring of both males and females. Superfetation re- 